\title{
FRATURA DO ESCAFOIDE POR ESTRESSE EM GINASTA: RELATO DE CASO
}

\author{
SCAPHOID STRESS FRACTURE IN GYMNASTICS ATHLETE: \\ A CASE REPORT
}

João Carlos Nakamoto', Mateus Saito', Ana Paula Cunha'2, Isabela Ugo Luques³

\section{RESUMO}

Apresenta-se o relato de caso de um ginasta de 18 anos de idade, que recebeu o diagnóstico de fratura por estresse do escafoide combinada com epifisiólise distal do rádio, e descreve-se seu tratamento. Após breve revisão da literatura sobre essa rara associação de lesões, os autores pedem atenção para a importância do exame físico e de imagem no correto diagnóstico e na observação de possíveis lesões combinadas.

Descritores - Epífise descolada; Fraturas de estresse; Punho

\section{ABSTRACT}

We present a case report of an 18 year-old gymnast who was diagnosed with a scaphoid stress fracture associated with a distal radial epiphysiolysis, reporting the treatment of choice. After a brief literature review about this rare association, the authors ask for attention concerning the importance of physical and image examination in making right diagnosis and finding associated injuries.

Keywords - Epiphyses, slipped; Fractures, stress; Wrist

\section{INTRODUÇÃO}

Fraturas por estresse da extremidade inferior são comuns e frequentemente relacionadas com as atividades atléticas. Enquanto isso, as da extremidade superior são mais raras, com poucos casos descritos na literatura ${ }^{(1)}$. Fraturas do escafoide são diagnosticadas por uma história de trauma agudo do punho em dorsiflexão, dor na sua face radial, à palpação do escafoide e na tabaqueira anatômica ${ }^{(2,3)}$.

Pacientes que apresentem queixas similares sem história de lesão aguda, mas que realizem atividades envolvendo estresse repetitivo, devem ser cuidadosamente examinados e levantar-se a hipótese de fratura do escafoide por estresse ${ }^{(1,4)}$.

É importante atentar ao fato de as implicações dos movimentos repetitivos de dorsiflexão e compressão do punho serem, frequentemente, relacionadas com as lesões da placa de crescimento do rádio, com evidências radiográficas de abertura e irregularidade da fise radial distal ${ }^{(5,6)}$.
Embora a dor no punho em ginastas seja classificada como "normal e consequência direta do esporte"(2), a queixa de dor nesses jovens atletas deve ser cuidadosamente avaliada.

Relatamos a seguir o caso de um ginasta que apresentava uma fratura por estresse do escafoide associada à epifisiólise distal do rádio.

\section{RELATO DO CASO}

Um ginasta de 18 anos de idade foi avaliado com queixa de dor insidiosa e crescente no punho direito. Sua rotina de treinos era de seis horas por dia, três dias por semana, nos últimos sete anos.

Aproximadamente, três meses antes da visita ao médico, iniciou quadro de dor severa no punho, com piora à extensão, especialmente nas atividades de salto no cavalo e nas barras paralelas.

3 - Fisioterapeuta do Instituto Vita; Mestre em Ciências Morfofuncionais pelo ICB-USP. 
Inicialmente, acreditava ser uma lesão muscular e tratou conservadoramente, aplicando gelo e reduzindo a atividade esportiva, mas com pouca melhora. Não havia história de dor ou trauma no punho acometido.

O exame físico revelou a presença de calosidades cutâneas sobre o rádio distal e escafoide direitos. O paciente relatou dor na tabaqueira anatômica e na epífise radial distal. Apresentava $38^{\circ}$ de extensão do punho à direita e $60^{\circ}$ à esquerda. A amplitude de movimento estava limitada a $12^{\circ}$ de desvio radial no punho direito, porém, sem limitações à flexão e desvio ulnar do mesmo. A avaliação da força de preensão da mão direita mostrou 46,5 quilogramas-força (kgf) e, na esquerda, 81,5kgf. Pronação, supinação e mobilidade digital encontravamse dentro dos limites de normalidade.

Uma radiografia posteroanterior do punho mostrou uma fratura na cintura do escafoide e uma abertura do aspecto radial da epífise radial distal (Figura 1). A ressonância nuclear magnética (RNM) foi realizada e evidenciou uma fratura completa da cintura do escafoide e um sinal representativo de edema de medula óssea nos polos proximais e distais. Apresentava ainda um edema na porção radial da fise, sugerindo um descolamento (Figuras 2 e 3 ).

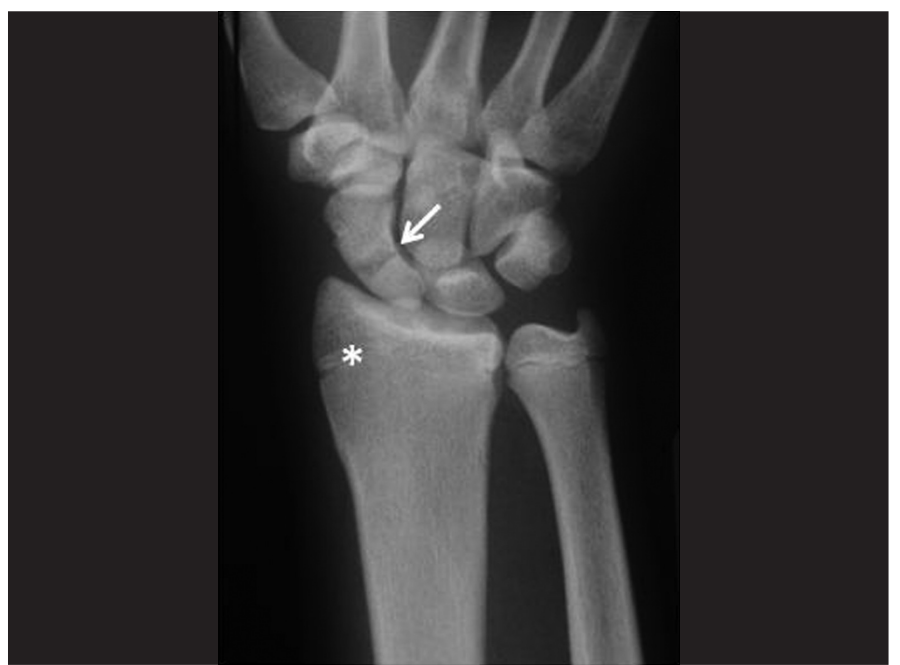

Figura 1 - Radiografia coronal com fratura na cintura do escafoide (seta) e abertura do aspecto radial da epífise radial distal $\left(^{*}\right)$

Optou-se pelo tratamento cirúrgico com fixação percutânea do escafoide e fixação in situ do processo estiloide do rádio (Figura 4).

Na primeira semana de pós-operatório utilizou-se uma órtese longa, que imobilizava a articulação metacarpofalangiana do polegar, e iniciou-se a reabilitação com o objetivo de controlar o edema, tratar a cicatriz e

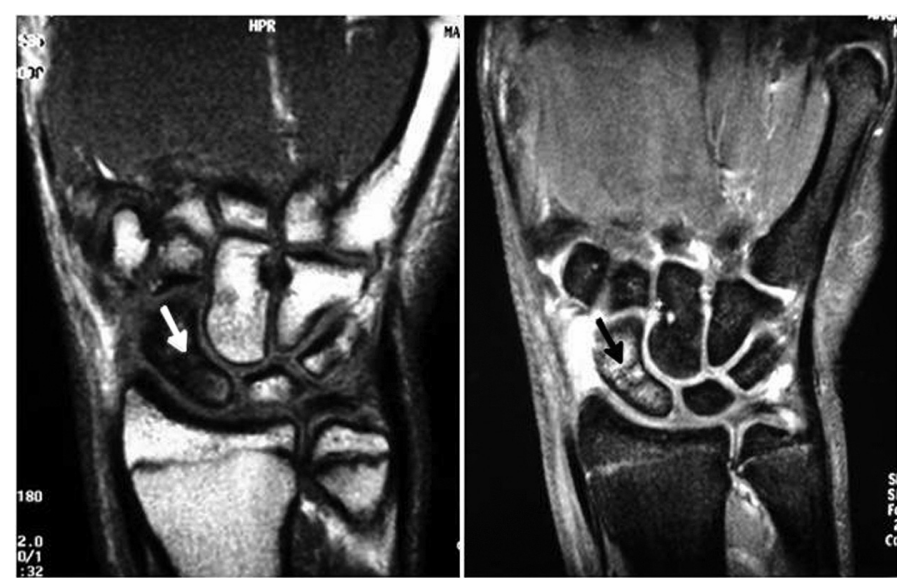

Figuras 2 e 3 - Imagem de ressonância magnética em T1 e T2. O corte coronal mostra uma fratura completa na cintura do escafoide (seta) e um sinal representativo de edema de medula óssea nos polos proximal e distal.

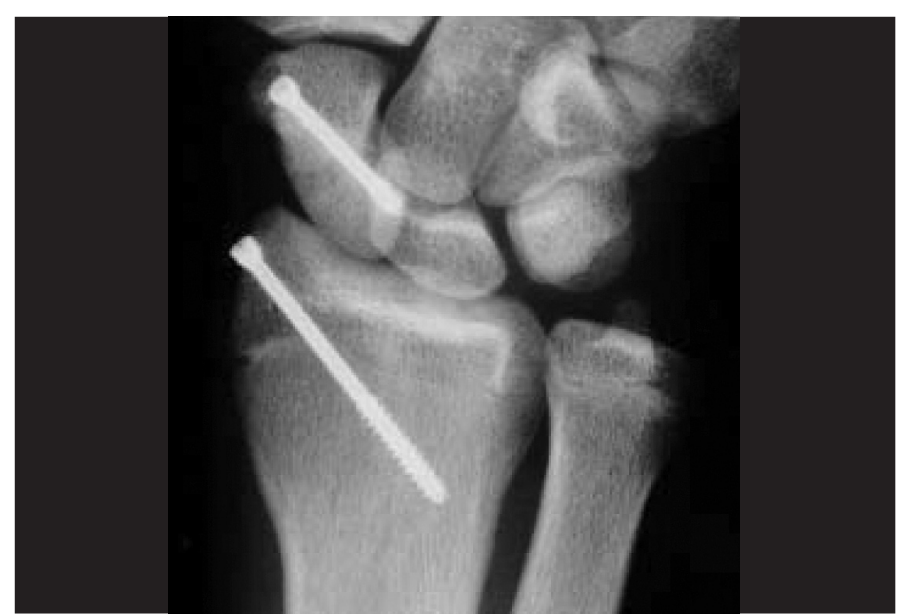

Figura 4 - Radiografia com incidência posteroanterior mostra a fixação percutânea e a fixação in situ do processo estiloide do rádio oito semanas após a cirurgia

aumentar a amplitude de movimento. Após oito semanas, radiografias mostraram sinais de consolidação e ao exame físico o punho apresentou $52^{\circ}$ de extensão, $62^{\circ}$ de flexão, $12^{\circ}$ de desvio radial e $20^{\circ}$ de desvio ulnar. A força de preensão da mão direita alcançou 66kgf.

$\mathrm{Na} 12^{\mathrm{a}}$ semana o paciente pôde retornar às atividades físicas progressivamente; com 16 semanas, ele retornou ao treino nos aparelhos.

À avaliação final, seis meses após a cirurgia, o atleta estava competindo sem queixas.

\section{DISCUSSÃO}

A dor no punho é um sintoma comum nos ginastas ${ }^{(7)}$. Dobyns e Gabel $^{(3)}$ relataram que $88 \%$ dos ginastas experimentam dor no punho durante a atividade e que $80 \%$ a $90 \%$ das lesões são secundárias à sobrecarga mecânica constante. 
O escafoide é o osso mais fraturado do carpo. Apresenta como característica a dificuldade de diagnóstico, devido ao seu tamanho reduzido e ao seu formato irregular. Outra característica importante é o risco de evolução para a pseudartrose ou a necrose avascular, decorrentes de a circulação do polo proximal ser dependente de vasos que cruzam a cintura desse osso.

Apesar da alta incidência relativa de lesões, a fratura por estresse do escafoide é relativamente rara, com apenas algumas citações na literatura ${ }^{(1,3-5,8-10)}$. Mais raras ainda são as fraturas associadas à epifisiólise traumática.

Previamente ao surgimento dos sintomas, o nosso atleta realizou atividades repetitivas que reproduziam o mecanismo da fratura aguda. Essas atividades foram realizadas em grande intensidade devido ao calendário de competições que se aproximavam. Todavia, não há registro de um trauma mais intenso que tenha desencadeado os sintomas. $\mathrm{O}$ fato de a dor ter se instalado de maneira insidiosa descarta a possibilidade de uma fratura aguda não diagnosticada. Outra característica relacionada com a fratura por estresse é a presença do edema ósseo em todo o escafoide.

A lesão epifisária concomitante observada na radiografia e na RNM apresentou-se como um fator complicador da fratura do escafoide, necessitando de atenção maior ao punho.

Weiker ${ }^{(5)}$ propôs que as lesões nos punhos dos ginastas são decorrentes de uma fraqueza na musculatura do punho e nos dedos dos ginastas. Essa fraqueza impede o amortecimento adequado do impacto no movimento de dorsiflexão do punho. Dessa maneira, há impacto no rádio distal e nos ossos do carpo. Os ligamentos volares do punho protegem o polo proximal do escafoide enquanto a sua porção distal fica exposta ao impacto. O ponto mais fraco do escafoide é a cintura, localizada imediatamente distal aos ligamentos volares e, portanto, o local mais provável da lesão. Esse princípio vale para as fraturas por estresse, através de forças repetitivas aplicadas em menor intensidade que aquelas necessárias para desencadear a fratura aguda.

Os motivos para a opção pelo tratamento cirúrgico do escafoide e do rádio distal foram: a) a possibilidade de estabilização absoluta de uma fratura potencialmente instalada havia alguns meses e que seria poupada do risco de desvio e, consequentemente, de um procedimento cirúrgico maior; b) a possibilidade de reabilitação precoce com ganho de amplitude de movimento ao mesmo tempo em que aconteceria o fortalecimento da musculatura intrínseca e extrínseca do punho; e c) o melhor controle de duas lesões próximas.

A terapia de mão procurou otimizar ao máximo a reabilitação, para permitir retorno precoce às atividades esportivas no menor tempo possível.

A dor crônica no punho do ginasta, mesmo sem história de um trauma agudo, deve levantar a suspeita de uma possível fratura por estresse do escafoide. A radiografia é o exame inicial de escolha, porém, muitas vezes, não é capaz de demonstrar a lesão. Nos casos suspeitos, a ressonância magnética é o exame de escolha. Mesmo a cintilografia óssea pode ser negativa, como mostra a série de Hanks et $a l^{(11)}$. Para os atletas de alto rendimento, talvez o tratamento cirúrgico represente uma possibilidade de retorno mais precoce ao esporte.

\section{REFERÊNCIAS}

1. Webb BG, Rettig LA. Gymnastic wrist injuries. Curr Sports Med Rep. 2008;7(5):289-95.

2. Manzione M, Pizzutillo PD. Stress fracture of the scaphoid waist: a case report. Am J Sports Med. 1981;9(4):268-9.

3. Dobyns JH, Gabel GT. Gymnast's wrist. Hand Clin. 1990;6(3):493-505.

4. Aronen JG. Problems of the upper extremity in gymnasts. Clin Sports Med. 1985;4(1):61-71.

5. Weiker GG. Hand and wrist problems in the gymnast. Clin Sports Med. 1992;11(1): 189-202.

6. Coady CM, Micheli LJ. Stress fractures in the pediatric athlete. Clin Sports. 1997; 16(2):225-36.
7. Matzkin E, Singer DI. Scaphoid stress fracture in a 13-year-old gymnast: a case report. J Hand Surg Am. 2000;25(4):710-3.

8. Gabel GT. Gymnastic wrist injuries. Clin Sports Med. 1998;17(3):611-21.

9. Inagaki H, Inoue G. Stress fracture of the scaphoid combined with the distal radial epiphysiolysis. Br J Sports Med. 1997;31(3):256-7.

10. Linscheid RL, Dobyns JH. Athletic injuries of the wrist. Clin Orthop Relat Res. 1985;(198):141-51.

11. Hanks GA, Kalenak A, Bowman LS, Sebastianelli WJ. Stress fractures of the carpal scaphoid: a report of four cases. J Bone Joint Surg Am. 1989;71(6):938-41. 